RESEARCH ARTICLE

\title{
Effectiveness of Telemedicine for Distant Wound Care Advice to- wards Patient Outcomes: Systematic Review and Meta-Analysis
}

\author{
Ling Jia Goh* and Xiaoli Zhu
}

Department of Nursing, National Healthcare Group Polyclinics, Singapore

*Corresponding author: Ling Jia Goh, Department of Nursing, National Healthcare Group Polyclinics (Hougang), 89 Hougang Avenue 4, Singapore 538829, Singapore, E-mail: ling_jia_goh@nhgp.com.sg

\begin{abstract}
Background: Telemedicine in wound care allows the general practitioner to communicate with the specialist via telecommunications in co-managing the patients' wounds thus effectively reducing the wait for specialist, allowing patients to get treated faster. As patients with complicated wounds increased, the demand for specialist wound care advice increased. To better manage our patients with chronic wound conditions, there is a need to source out new modalities in wound care management. Though there were many studies done on telecommunications in wound care, a review was necessary as the outcomes measured varied widely with inconsistent evidence on its clinical effectiveness. The aim of this review was to evaluate whether the use of telemedicine for distant wound care advice was effective in improving wound outcomes through meta-analysis of the combined trials.

Methods: Database searches were performed in Medline, EMBASE and CINAHL. Study methodologies were assessed using Cochrane Collaboration risk-of-bias tool and JBI-MASTARI.

Results: 4 randomized controlled trials and before-and-after studies involving 274 wounds were involved in the meta-analysis and studies were of low to moderate risk of bias. The combined trial of 3 studies comprising 229 wounds evaluating wound healing rates showed significant improvement in wound healing (RR 1.50, $\mathrm{Cl} 1.06$ to 2.13, p = 0.02). However, there was no significant change in wound size (MD 3.86, Cl 5.04 to $12.75, p=0.40$ ).

Conclusion: Our review suggests that the use of telemedicine in wound care could effectively improve wound healing rate but not the change in wound size. Hence, more randomized controlled trials are still needed to prove its effectiveness in the clinical area.
\end{abstract}

\section{Keywords}

Telemedicine, Wound care, Review, Patient outcomes, Wound healing rate, Wound size

\section{Introduction}

The advancement in telecommunications and development in telemedicine offer promising potential for setting up tele-wound care program. Telemedicine, a provision of healthcare consultation and education using telecommunication networks to communicate information, has existed for more than 30 years [1]. In wound care, this could be done as a direct means of consultation which allows patient to receive consultation directly with the wound care specialist via telecommunications thus eliminating the need for conventional face-to-face visits. It could also be done as an indirect consultation where the general practitioner communicates with the specialist in co-managing the patients' wounds thus effectively reducing the wait for specialist, allowing patients to get treated faster. Store and forward and real-time video conferencing are the two common modalities in telemedicine in wound care.

As Singapore enters an ageing and affluent society, the number of chronic complicated wounds has risen substantially. Elderly population had grown steadily from $7.8 \%$ in 2002 to $11.7 \%$ in 2013 [2] and diabetic population had increased from $8.2 \%$ in 2004 to $11.3 \%$ in 2010 [3]. Elderly tend to have significant co-morbidity and are more likely to be on poly pharmacy which could impact wound healing [4]. Diabetic patients have poorer wound healing process due to the poorer blood circulation to wound site, proneness to infection and presence of neuropathy [4].

In our polyclinics, the number of complex wound cases have increased steadily from $46 \%$ in 2012 to $55 \%$ 
in 2014 and this percentage is expected to increase in the coming years, propelling the demand for specialist wound care advice. To better manage our patients with chronic wound conditions, there is a need to source out new modalities in wound care management.

Many studies were done on evaluating telemedicine in wound care as an indirect means of wound consultation however the measured outcomes varied widely in these studies with inconsistent evidence on its clinical effectiveness thus necessitating a review.

The aim of this review was to evaluate whether the use of telemedicine for distant wound care advice was effective in improving wound outcomes through meta-analysis of the combined trials.

\section{Methods}

\section{Search strategy}

A search was performed in the following bibliographic databases for relevant articles from inception to September 2015: CINAHL Plus with Full Text, EBSCO Medline Complete, OVID EMBASE. We developed a search strategy for CINAHL Plus with Full Text and adapted it to other databases. Key search words were "tele-wound care", "tele-medicine", "chronic wound", "leg ulcer", "wound management" and "wound care". Relevant articles were retrieved full-text and reference lists of these articles were reviewed to avoid missing any studies. A search performed in the grey literature, specifically the Open Grey data base, revealed no relevant articles. Due to limitations in time and resources, we did not perform any hand-searches of key journals. To minimize language bias, relevant articles published originally in other languages other than English were also included but these articles had to be translated to English language from the original language, either by the database or foreign language translator. A copy of the CINAHL Plus with Full Text search strategy was attached in the Table 1.

\section{Inclusion and exclusion criteria}

Primary studies with the following design characteristics were included:

(a) Population

- Participants above 18 years of age

- Participants with any type of wounds requiring wound management

Table 1: Search strategy for CINAHL PLUS with full text (last run on 22.9.15).

\begin{tabular}{|l|l|l|l|}
\hline 1 & Telemedicine & 9 & Wound assessment \\
\hline 2 & Telenursing & 10 & Wound consultation \\
\hline 3 & Tele-wound care & 11 & Wound dressing \\
\hline 4 & Tele* $^{*}$ & 12 & Leg ulcer \\
\hline 5 & OR/1-4 & 13 & Ulcer \\
\hline 6 & Wound care & 14 & Chronic wound \\
\hline 7 & Wound management & 15 & OR/6-14 \\
\hline 8 & Wound nursing & 16 & 5 AND 15 \\
\hline
\end{tabular}
(b) Intervention

- Store and forward modality between wound expert and general professional

- $\quad$ Real time video conferencing between wound expert and general professional

- Generating images using mobile phone then transmit image to expert via email

We excluded studies with direct patient consultation because the purpose of the review was to assess the effectiveness of using telecommunication between a professional wound expert and a general trained professional in providing distant wound care advice.

(c) Comparison

- Standard wound care management

- Face-to-face wound care management

(d) Outcomes

- Wound healing rates

- Wound condition

- Symptom control

- Patient satisfaction rates

We excluded studies with outcomes that evaluated the agreement and accuracy between face to face and remote wound assessment/management. Studies with outcomes that measured the healthcare professionals' satisfaction rates and confidence level with the use of tele-medicine were also excluded. This review was directed towards patient outcome and not a review of feasibility thus the exclusion of the above outcomes.

(e) Study design

- Randomized controlled trial

- Pilot randomized controlled trial

- Non-randomized trials

- Controlled before-after studies

- Prospective cohort studies with a comparison of treated and non-treated groups

We included studies reported in peer reviewed publications and excluded conference abstracts and posters. As this review was assessing the effectiveness of intervention, experimental studies were the best study design to answer this question but in view of the difficulty in implementing experimental trial for this topic of interest, we anticipated that many of these studies were observational study hence we included observational studies that were of higher hierarchy. We excluded studies using case control and case studies because these study designs were inappropriate to address the review question.

\section{Study selection}

GL and ZXL independently performed searches in all 
Table 2: Table for exclusion of studies for not meeting eligibility criteria.

\begin{tabular}{|c|c|c|}
\hline 1 & Yderstraede, et al. [13] & Study design: Editorial comment \\
\hline 2 & Wiseman, et al. [14] & Study design: Survey of patient's willingness to adopt a smartphone-based system \\
\hline 3 & Dobke, et al. [15] & Study design: Survey \\
\hline 4 & Lazzarini, et al. [11] & Study design: Survey \\
\hline 5 & Salcido [16] & Study design: Editorial comment \\
\hline 6 & Wilkins, et al. [12] & Study design: Descriptive \\
\hline 7 & King [17] & Study design: A case study \\
\hline 8 & Litzinger, et al. [18] & Study design: A case study and survey \\
\hline 9 & Kanthraj [19] & Study design: Traditional review \\
\hline 10 & Weber, et al. [20] & Study design: Traditional review \\
\hline 11 & Hammett, et al. [21] & Study design: Traditional review \\
\hline 12 & Lowery, et al. [22] & Study design: A case report \\
\hline 13 & Clemensen, et al. [23] & Study design: Traditional review \\
\hline 14 & Broder, et al. [24] & Study design: Traditional review \\
\hline 15 & Villar Rojas, et al. [25] & Study design: A case study \\
\hline 16 & Foltynski, et al. [26] & Study design: Traditional review \\
\hline 17 & Jones, et al. [27] & Study design: Traditional review \\
\hline 18 & Kobza, et al. [28] & Study design: Traditional review \\
\hline 19 & Salles, et al. [29] & Study design: Traditional review \\
\hline 20 & Mathewson, et al. [30] & Study design: A case study \\
\hline 21 & Dobke, et al. [10] & Study design: Case series \\
\hline 22 & Jelnes [31] & Study design: Traditional review \\
\hline 23 & Ong [32] & Study design: Traditional review \\
\hline 24 & Ablaza, et al. [33] & Study design: Traditional review \\
\hline 25 & Chanussot-Deprez, et al. [34] & Study design: Traditional review \\
\hline 26 & Chanussot-Deprez, et al. [35] & Study design: Traditional review \\
\hline 27 & Samad, et al. [36] & Study design: Traditional review \\
\hline 28 & Sarhan, et al. [37] & Study design: Retrospective review \\
\hline 29 & Visco, et al. [38] & Study design: Case study \\
\hline 30 & Stern, et al. [39] & Study design: Mixed methods study \\
\hline 31 & Bowns, et al. [40] & Population: Malignant melanoma or squamous cell carcinoma \\
\hline 32 & De'Ath, et al. [41] & Population: Patients with CXR and ECG \\
\hline 33 & Williams [42] & Intervention: Testing feasibility of new system \\
\hline 34 & Larsen, et al. [43] & Intervention: Testing feasibility of new system \\
\hline 35 & Laflamme, et al. [44] & Outcome: Evaluation of fact-to-face and videoconferencing encounters \\
\hline 36 & Kim, et al. [45] & Outcome: Comparing accuracy of assessment and evaluation \\
\hline 37 & Terris, et al. [46] & Outcome: Comparing accuracy of wound image \\
\hline 38 & Van Dillen, et al. [47] & Outcome: Comparing accuracy of wound image \\
\hline 39 & Chen, et al. [48] & Outcome: Comparing accuracy of assessment \\
\hline 40 & Dobke, et al. [15] & Outcome: Satisfaction and decisional conflict scale score \\
\hline 41 & Houghton, et al. [49] & Outcome: Comparing accuracy of assessment \\
\hline 42 & Bowling, et al. [50] & Outcome: Comparing accuracy of assessment \\
\hline 43 & Gardner, et al. [51] & Outcome: Comparing accuracy of assessment \\
\hline 44 & Debray, et al. [52] & Outcome: Comparing accuracy of assessment \\
\hline 45 & Hofmann-Wellenhof, et al. [53] & Outcome: Comparing accuracy of assessment \\
\hline 46 & Ratliff, et al. [54] & Outcome: Evaluate cost saving and quality of care \\
\hline 47 & Halstead, et al. [55] & Outcomes: Comparing accuracy between tele and in-person assessment \\
\hline 48 & Saffle, et al. [56] & Outcome: Improve resource utilization \\
\hline 49 & Clegg, et al. [57] & Outcome: Cost saving \\
\hline 50 & Rasmussen, et al. [58] & Outcome: Comparing accuracy between tele and in-person assessment \\
\hline 51 & Braun, et al. [59] & Outcome: Feasibility \\
\hline 52 & Clemensen, et al. [23] & Outcome: Feasibility \& cost \\
\hline 53 & Rintala, et al. [60] & Outcome: Acceptability \\
\hline 54 & Rees, et al. [61] & Outcome: Use of service (acceptability) and finacial outcome \\
\hline 55 & Lewis, et al. [62] & Outcome: Tele service utilization, providers' satisfaction \\
\hline 56 & Wirthlin [63] & Outcome: Feasibility \\
\hline 57 & Johnson-Mekota, et al. [64] & Outcome: Patients' and providers' satisfaction \\
\hline 58 & Chan, et al. [65] & Outcome: Using scoring scale \\
\hline 59 & Hill, et al. 2009 [66] & Outcome: Comparing accuracy of assessment \\
\hline 60 & Salmhofer, et al. [67] & Outcome: Comparing accuracy of assessment \\
\hline
\end{tabular}


three databases using the search strategy. All titles and abstracts of the identified articles were independently screened through the first literature search. Full texts of the relevant articles were then retrieved and assessed for eligibility. GLJ and ZXL independently read the articles to identify studies to be included in the review. The reference lists of the included studies were then examined to identify any potential studies that were left out. There was moderate agreement between the two reviewers (Cohen kappa $=0.448$ ). In cases of uncertainty or discrepancies between the reviewers, a discussion was arranged to reach consensus.

\section{Data extraction procedure}

A data extraction form was developed to record the relevant study characteristics and this form was piloted on at least one study in the review. Data extracted from the included studies were: study design, population characteristics, setting, intervention and control group characteristics, outcome characteristics and results. GLJ and $Z X L$ independently filled in the data extraction form and any discrepancies between the reviewers were discussed to reach a consensus.

\section{Assessment of risk of bias}

GLJ and ZXL independently assessed the risk of bias in the included studies. RCTs were assessed using Cochrane Collaboration risk-of-bias tool for randomized trials and studies were assessed to evaluate whether there were random sequence generator; allocation concealment; blinding of participant, personnel and outcome assessor; incomplete outcome data; and selective reporting. Non-randomized and observational studies were assessed using JBI-MASTARI and these studies were assessed to evaluate whether there was bias due to confounding; selection of participants into study; measurement of interventions; departures from intended interventions; missing data; measurement of outcomes; and selection of reported result. Any disagreements in quality assessment were resolved by discussion.

\section{Synthesis of results and quality assessment}

For continuous variable, the Standardized Mean Difference (SMD) with 95\% confidence interval was computed whereas for dichotomous variables, the Risk Ratio (RR) with $95 \%$ confidence interval was computed. Chi-

Table 3: Prisma flowchart.

Relevant articles identified by database $(n=2019)$<smiles>C1CCCCC1</smiles>

Relevant papers after screening through abstract and title $\underline{(\mathrm{n}=118)}$

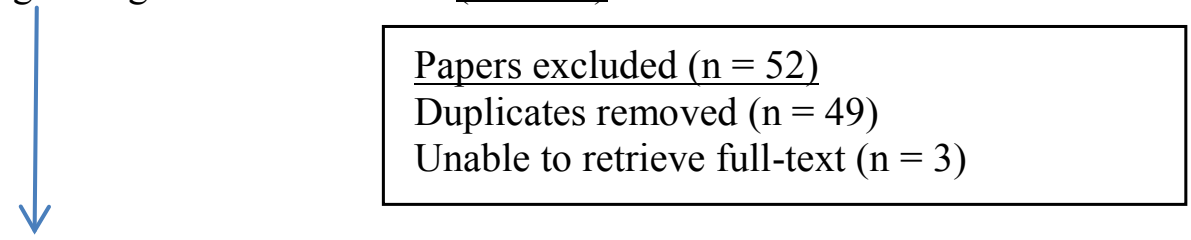

Full-text papers retrieved for detailed examination $\underline{(\mathrm{n}=66)}$

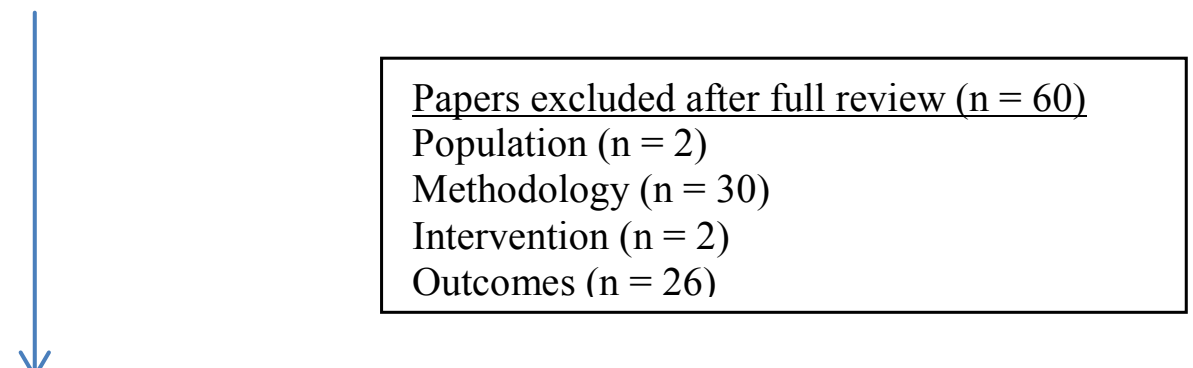

Papers retrieved for methodological quality $\underline{(\mathrm{n}=6)}$

Papers excluded after quality assessment $(\mathrm{n}=1)$ Control contamination $(\mathrm{n}=1)$

Trials included in systematic review $\underline{(\mathrm{n}=5)}$

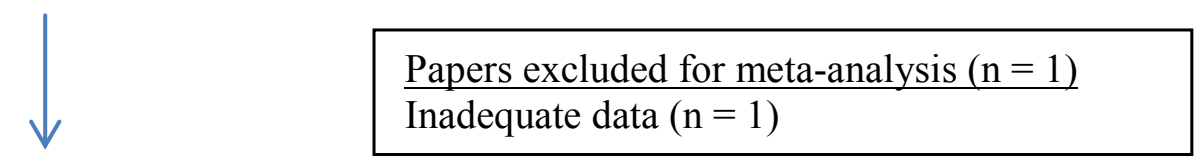

Trials included in meta-analysis $\underline{(\mathrm{n}=4)}$ 
square test was used to test for heterogeneity across studies and $p<0.1$ indicated heterogeneity. When studies showed heterogeneity, $\mathrm{I}^{2}$ would be used to measure the variability present due to heterogeneity rather than chance. $\mathrm{I}^{2}$ values of $25 \%, 50 \%$ and $75 \%$ were used to denote low, moderate, and high heterogeneity. Investigations would then be conducted to explain the heterogeneity. For homogenous studies, fixed effects model was used to calculate the pooled treatment effect estimates. When there is obvious heterogeneity and adequate support for heterogeneity, random effects model would be used. Meta-analysis was performed using Review Manager (RevMan 5.3) and a forest plot would be illustrated. When meta-analysis could not be performed for the combined studies, the data would be presented in a narrative form.

\section{Results}

\section{Search results}

2019 records were identified through the database searches. After screening through the abstract and title, only 118 articles were viewed as relevant. Of these, 52 articles were excluded because of duplicates and the inability to retrieve for full-text. 66 full-text articles were retrieved for detailed examination and of these, 60 articles were excluded because they did not fit the eligibility criteria (Table 2). 6 articles were evaluated for methodological quality and one study was excluded as the intervention deviated from the aim of this review. In total, 5 articles were considered for the systematic review but only 4 articles were included in the meta-analysis. (Table 3, Prisma flowchart).

\section{Study characteristics and participants}

Table 4 provides a table describing the characteristics of the 5 included studies. There were three randomized controlled trial, one cluster controlled trial and one before and after study. In the cluster controlled trial, randomization was not done due to ethical issues. Altogether, these trials evaluated the wound outcomes in 300 patients involving 375 wounds and this was excluding subjects in Group B in one of the studies because these subjects were neither considered to be in the interventional group nor the control group [5]. Due to inadequate data in one study, only 207 patients involving 282 wounds were considered for meta-analysis [6]. However out of the 282 wounds, 8 were not included in the meta-analysis as patients either died, lost to follow up or withdrew from the study resulting in only 274 wounds analyzed. These studies took place in Austria, Australia, UK, USA and Denmark. Wounds that were included in these studies were non-healing wounds, stasis wounds, leg ulcers, foot ulcers and pressure ulcers.

\section{Intervention and control}

The interventions in these studies involved having the home care nurses sending digital images electroni- cally to the remote wound care experts weekly or every 2 weeks. The home care nurses would then act upon the instructions of the wound care experts to manage the patients' wounds. In the control group, the home care nurses solely managed the patients' wound and would refer the patients to the wound care experts only when they assessed that it was necessary.

\section{Outcome and results}

Healing rate was much better in the interventional group in 3 out of the 4 studies. In 2 studies, wound improved or completely healed in $70 \%$ of patients in the interventional group while only $18 \%-45 \%$ of the wounds were improved or completely healed in the control group [7,8]. The interventional group had wounds healed $11.7 \%$ faster than the control group [4]. In the before and after study, $71 \%$ of the wounds improved after 3 months of intervention [9]. These results were in contrast with one study where $88 \%$ of the wounds in the control group improved or healed and this was $3 \%$ more than in the interventional group [5]. The interventional group also took 16 days slower to heal than the control group [5].

Only 2 studies evaluated the amount of change in wound size. In the before and after study, there was a decrease of average $3.92 \mathrm{~cm}^{2}$ in wound size 3 months after the intervention [9]. In another study, the change in wound size in the interventional group was 3.57 $\mathrm{cm}^{2}$ more than that of the control group but it was not known whether the wound size was increased or decreased in the interventional group [5].

\section{Risk of bias}

Risks of bias in these studies were low to moderate. Randomization was done in 3 of these studies however randomization procedure was not thoroughly explained except for one study where the authors described that computer program was used to generate random sequence. Though authors did not explain how performance and detection bias was avoided, the authors mentioned that double blinding was not possible due to nature of interventions. In the controlled trial where randomization was not done, the author gave sufficient explanation and to avoid bias brought by non-randomization, several important covariates were adjusted in the results. Authors took precautions to avoid protocol deviations and control contamination and when these unfortunately occurred, the involved participants were withdrawn from the study. No bias or confounding factors were detected in the before and after study.

\section{Discussion}

This systematic review showed that use of telemedicine for expert wound care advice was significant in improving wound healing rates for patients with non-healing, chronic wounds or ulcers but not significant in the change in wound size. 4 out of the 5 studies had pos- 


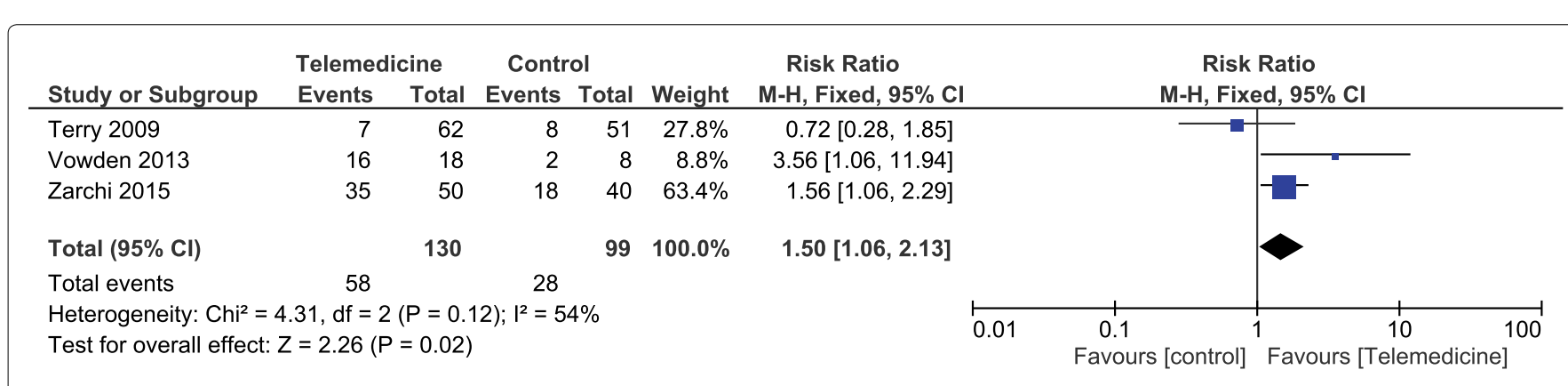

Forest plot 1: Wound healing rate in the combined trial of 3 studies.

\begin{tabular}{|c|c|c|c|c|c|c|c|c|c|c|}
\hline Study or Subgroup & Experimental & $\begin{array}{l}\text { ental } \\
\text { Total }\end{array}$ & \multicolumn{2}{|c|}{ Control } & Weight & $\begin{array}{c}\text { Risk Ratio } \\
\text { M-H, Fixed, 95\% Cl }\end{array}$ & \multicolumn{4}{|c|}{$\begin{array}{c}\text { Risk Ratio } \\
\text { M-H, Fixed, 95\% Cl }\end{array}$} \\
\hline Terry 2009 & 53 & 62 & 45 & 51 & $0.0 \%$ & $0.97[0.84,1.12]$ & & & & \\
\hline Vowden 2013 & 16 & 18 & 2 & 8 & $12.2 \%$ & $3.56[1.06,11.94]$ & & & & \\
\hline Zarchi 2015 & 35 & 50 & 18 & 40 & $87.8 \%$ & $1.56[1.06,2.29]$ & & & - & \\
\hline Total $(95 \% \mathrm{Cl})$ & & 68 & & 48 & $100.0 \%$ & $1.80[1.23,2.63]$ & & & & \\
\hline Total events & 51 & & 20 & & & & & & & \\
\hline $\begin{array}{l}\text { Heterogeneity: } \mathrm{Chi}^{2} \\
\text { Test for overall effec }\end{array}$ & $\begin{array}{l}1.76, \mathrm{df}= \\
Z=3.04\end{array}$ & $\begin{array}{l}=1(P= \\
(P=0.0\end{array}$ & $\begin{array}{l}0.19) ; I^{2} \\
02)\end{array}$ & $=43 \%$ & & & 0.005 & $\begin{array}{l}0.1 \\
\text { purs [control] }\end{array}$ & $\begin{array}{r}1 \\
\text { Favours [e }\end{array}$ & $\frac{1}{200}$ \\
\hline
\end{tabular}

Forest plot 2: Wound healing rate in the 2 studies after removal of a slightly different study.

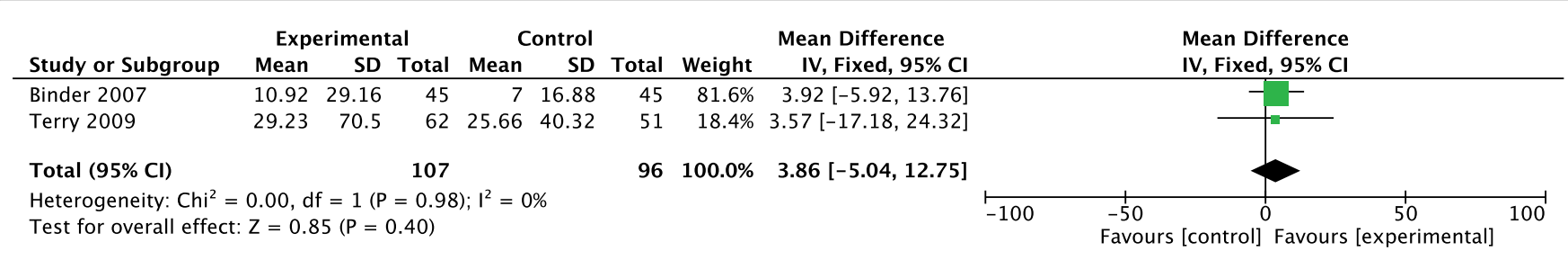

Forest plot 3: Change in wound size $\left(\mathrm{cm}^{2}\right)$.

itive results and the combined trial of 3 studies comprising 229 wounds showed significant improvement in wound healing ( $R R 1.50, \mathrm{Cl} 1.06$ to $2.13, \mathrm{p}=0.02$ ) (Forest plot 1). Wound healing was measured by the number of wounds healed at the end of the study. Fixed effect model was used in the analysis as the combined trials showed homogeneity among studies as $p>0.1$ $(p=0.12)$, though there was moderate heterogeneity as $1^{2}=54 \%$. Moderate heterogeneity was the result of one trial slightly different from the other 2 trials $[5,7,8]$ and the authors explained that though randomization was done but by chance, the interventional group had patients with wounds significantly larger than the control group. The removal of that trial from the analysis showed that the combined trials of the 2 studies comprising 116 wounds had moderately low heterogeneity $\mathrm{I}^{2}=43 \%$ with fixed effect model showing significant improvement in wound healing (RR $1.80, \mathrm{Cl} 1.23$ to $2.63, \mathrm{p}$ $=0.002$ ) (Forest plot 2). The combined trial of 2 studies that evaluated change in wound size showed no significant change in the wound size (MD 3.86, $\mathrm{Cl} 5.04$ to $12.75, p=0.40$ ) (Forest plot 3) [9]. Fixed effect model was used as there was no differences between the studies $\left(1^{2}=0 \%, p=0.98\right)$.

A weakness in this systematic review was due to the mix of study designs used in the meta-analysis. Howev- er, this paper provided insights on how telemedicine helped in improving wound healing rates. More randomized trials are still needed to evaluate the effectiveness of telemedicine in wound care. However, understandably, there are a lot of limitations in implementing such trials since telemedicine as an intervention costs a lot in the equipment and requires lots of resources in staff training. Hence, most randomized controlled trials were done in small scale. Study protocol should ensure appropriate randomization and measures should be taken to prevent bias so that good quality randomized controlled trial could be combined together to achieve a more significant outcome.

There were many trials evaluating feasibility of telemedicine in wound care however limited in evaluating patient and clinical outcomes. These trials had shown that there was good agreement between wound images sent via telecommunications and seeing the wound in person hence the next step of advancing research in the area of telemedicine in wound care would be evaluating on patient and clinical outcomes.

Telemedicine in wound care could be implemented in areas where there were limited access to wound care specialist. In conventional face to face consults, patients either have to wait for their appointment to see wound 
care specialist or the wound care specialist has to make a trip to see the patient for those with mobility difficulties. Both of which, resulted in long waiting time to get advice from the wound care specialist. In our clinical area, telemedicine would prove to be useful in gaining faster advice from wound care specialist. The community or homecare nurse could communicate with the wound care nurse specialist to get her recommendations in managing patients' wounds. Two surveys done in 2010 found that $93 \%$ to $100 \%$ of general practitioners agreed that telemedicine wound care consult was a useful tool in their practice and were satisfied with the telemedicine consult service $[10,11]$. An observational study found that $98.2 \%$ of patients were satisfied with the care using telemedicine [12].

\section{Conclusion}

Telemedicine in wound care allowed the patient to gain faster wound care advice from the specialist and this logically would translate into faster wound healing rate. The result of this systematic review had proven that telemedicine in wound care indeed improved wound healing rate. However, whether it helped in reducing the wound size in a given period remained inconclusive hence more randomized controlled trial should be done in evaluating clinical outcomes to prove its effectiveness in the clinical settings.

As we move towards delivering quality healthcare, patient-centered care, involving patients in decision making and working alongside with them, becomes important. Thus, future research should not just focus on the clinical aspect of the intervention but also incorporate patient outcomes such as patient satisfaction or patients perceptions' of using telemedicine in wound care in the study.

\section{Acknowledgement}

Special thanks to the Department of Nursing, NHGP Singapore for the tremendous support given in completing this systematic review.

\section{References}

1. Kearney JM (1997) Telemedicine: ringing in a new era of health care delivery. CommLaw Conspectus 5: 289-303.

2. International Longevity Centre Singapore (2011) A profile of older men and older women in Singapore 2011.

3. Health Promotion Board (2011) Information paper on diabetics in Singapore.

4. Vowden P (2011) Hard to heal wounds. Wounds International 2: 1-6.

5. Terry M, Halstead LS, O'Hare P, Gaskill C, Ho PS, et al. (2009) Feasibility study of home care wound management using telemedicine. Adv Skin Wound Care 22: 358-364.

6. Santamaria N, Carville K, Ellis I, Prentice J (2004) The effectiveness of digital imaging and remote wound consultation on healing rates in chronic lower leg ulcers in the Kimberley region of Western Australia. Primary Intention 12: 62-70.
7. Vowden K, Vowden P (2013) A pilot study on the potential of remote support to enhance wound care for nursing-home patients. Journal of Wound Care 22: 481-488.

8. Zarchi K, Haugaard VB, Dufour DN, Jemec GB (2015) Expert advice provided through telemedicine improves healing of chronic wounds: prospective cluster controlled study. J Invest Dermatol 135: 895-900.

9. Binder B, Hofmann-Wellenhof R, Salmhofer W, Okcu A, Kerl $\mathrm{H}$, et al. (2007) Teledermatological monitoring of leg ulcers in cooperation with home care nurses. Arch Dermatol 143: 1511-1514.

10. Dobke M, Renkielska A, De Neve J, Chao J, Bhavsar D (2006) Telemedicine for problematic wound management: enhancing communication between long-term care, skilled nursing, and home caregivers and a surgical wound specialist. Wounds 18: 256-261.

11. Lazzarini PA, Clark D, Mann RD, Perry VL, Thomas CJ, et al. (2011) Does the use of store-and-forward telehealth systems improve outcomes for clinicians managing diabetic foot ulcers? A pilot study. Journal of Foot and Ankle Research 4: 31 .

12. Wilkins EG, Lowery JC, Goldfarb S (2007) Feasibility of virtual wound care: a pilot study. Adv Skin Wound Care 20: 275-276, 278.

13. Yderstraede KB, Froekjaer J, Schnack B, Rasmussen B (2016) Response to comment on Rasmussen, et al. A randomized controlled trial comparing telemedical and standard outpatient monitoring of diabetic foot ulcers. Diabetes Care 39: e11.

14. Wiseman JT, Fernandes-Taylor S, Barnes ML, Tomsejova A, Saunders RS, et al. (2015) Conceptualizing smartphone use in outpatient wound assessment: patients' and caregivers' willingness to use technology. J Surg Res 198: 245-251.

15. Dobke MK, Bhavsar D, Gosman A, De Neve J, De Neve B (2008) Pilot trial of telemedicine as a decision aid for patients with chronic wounds. Telemed J E Health 14: 245-249.

16. Salcido RS (2010) Embracing telemedicine in wound care. Advances in Skin \& Wound Care 23: 391.

17. King B (2014) Influencing dressing choice and supporting wound management using remote "tele-wound care". Br J Community Nurs S24-S31.

18. Litzinger G, Rossman T, Demuth B, Roberts J (2007) Inhome wound care management utilizing information technology. Home Healthc Nurse 25: 119-130.

19. Kanthraj GR (2015) Patient-assisted teledermatology practice: what is it? When, where, and how it is applied? Indian J Dermatol Venereol Leprol 81: 136-143.

20. Weber SA, Watermann N, Jossinet J, Byrne JA, Chantrey $\mathrm{J}$, et al. (2010) Remote wound monitoring of chronic ulcers. IEEE Trans Inf Technol Biomed 14: 371-377.

21. Hammett L, Harvath TA, Flaherty-Robb M, Sawyer G, OIson D (2007) Remote wound care consultation for nursing homes: using a web-based assessment and care planning tool. J Gerontol Nurs 33: 27-35.

22. Lowery JC, Hamill JB, Wilkins EG, Clements E (2002) Technical overview of a web-based telemedicine system for wound assessment. Adv Skin Wound Care 15: 165-166, 168-169.

23. Clemensen J, Larsen S (2007) Cooperation versus coordination: using real-time telemedicine for treatment at home of diabetic foot ulcers. Journal Of Telemedicine \& Telecare 13: 32-35. 
24. Broder K, Chau D, Bodor R, Yourman L (2015) Skilled Nursing Facility/Plastic Surgery Interdisciplinary Team Approach: Utilizing Inter-Professional Collaboration and Innovative Telemedicine Technologies to Provide Comprehensive Wound Care Across the Healthcare Continuum. JAMDA 16: 22.

25. Villar Rojas AE, Villar Hernández ÁR (2014) 'Telecare Unit': New technologies in nursing care. Resolution of a pressure ulcer of a patient who lives in another province. Gerokomos 25: 131-134.

26. Foltynski P, Ladyzynski P, Wojcick JM (2012) Telemonitoring of diabetic foot ulcers being managed in the outpatient setting. Diabetic Foot Journal 15: 74-82.

27. Jones SM, Banwell PE, Shakespeare PG (2004) Telemedicine in wound healing. International Wound Journal 1: 225230.

28. Kobza L, Scheurich A (2000) The impact of telemedicine on outcomes of chronic wounds in the home care setting. Ostomy Wound Management 46: 48-53.

29. Salles N, Jenn J, Barateau M, Sarry O, Libert K, et al. (2013) Telemedicine consultation for patients with chronic wounds especially pressure ulcers. European Geriatric Medicine 4: S113.

30. Mathewson C, Adkins VK, Lenyoun MA, Schmidt AM, Jones ML (1999) Using telemedicine in the treatment of pressure ulcers. Ostomy Wound Manage 45: 58-62.

31. Jelnes $R$ (2011) Telemedicine in the management of patients with chronic wounds. J Wound Care 20: 187-190.

32. Ong CA (2008) Telemedicine and wound care. Stud Health Technol Inform 131: 211-225.

33. Ablaza V, Fisher J (1998) Wound care via telemedicine: the wave of the future. Home Health Care Consultant 5: 12-16.

34. Chanussot-Deprez C, Contreras-Ruiz J (2008) Telemedicine in wound care. International Wound Journal 5: 651-654.

35. Chanussot-Deprez C, Contreras-Ruiz J (2013) Telemedicine in wound care: a review. Advances in Skin \& Wound Care 26: 78-82.

36. Samad A, Hayes S, Dodds S (2002) Telemedicine: an innovative way of managing patients with leg ulcers. BJN 11: S38-S52.

37. Sarhan F, Weatherburn G, Graham A, Thiyagarajan C (2010) Use of digital images in the assessment and treatment of pressure ulcers in patients with spinal injuries in community settings. J Telemed Telecare 16: 207-210.

38. Visco DC, Shalley T, Wren SJ, Pieri Flynn J, Brem H, et al. (2001) Use of telehealth for chronic wound care: a case study. J Wound Ostomy Continence Nurs 28: 89-95.

39. Stern A, Mitsakakis N, Paulden M, Alibhai S, Wong J, et al. (2014) Pressure ulcer multidisciplinary teams via telemedicine: a pragmatic cluster randomized stepped wedge trial in long term care. BMC Health Serv Res 14: 83.

40. Bowns IR, Collins K, Walters SJ, McDonagh AJ (2006) Telemedicine in dermatology: a randomised controlled trial. Health Technol Assess 10: 1-39.

41. De'Ath HD, Stechman MJ, Gibson P, Bicknell C (2011) A pilot study examining the use of mobile camera phones as a teleconsultation tool in surgical practice. Journal of Communication in Healthcare 4: 102-105.

42. Williams C (2005) Home telehealth consultations: A pilot study to provide specialized nursing care to home health patients. JAAD 52: 211.
43. Larsen SB, Clemensen J, Ejskjaer N (2006) A feasibility study of UMTS mobile phones for supporting nurses doing home visits to patients with diabetic foot ulcers. J Telemed Telecare 12: 358-362.

44. Laflamme MR, Wilcox DC, Sullivan J, Schadow G, Lindbergh D, et al. (2005) A Pilot Study of Usefulness of Clinician Patient Videoconferencing for Making Routine Medical Decisions in the Nursing Home. J Am Geriatr Soc 53: 1380-1385.

45. Kim HM, Lowery JC, Hamill JB, Wilkins EG (2003) Accuracy of a Web-based System for Monitoring Chronic Wounds. Telemed J E Health 9: 129-140.

46. Terris DD, Woo C, Jarczok MN, Ho CH (2011) Comparison of in-person and digital photograph assessment of stage III and IV pressure ulcers among veterans with spinal cord injuries. Journal J Rehabil Res Dev 48: 215-224.

47. Van Dillen C, Silvestri S, Haney M, Ralls G, Zuver C, et al. (2013) Evaluation of an off-the-shelf mobile telemedicine model in emergency department wound assessment and management. J Telemed Telecare 19: 84-88.

48. Chen $\mathrm{CH}$, Young $\mathrm{TH}$, Huang $\mathrm{CH}$, Chang $\mathrm{HH}$, Chen $\mathrm{CL}$ (2014) Patient-centered wound teleconsultation for cutaneous wounds: a feasibility study. Ann Plast Surg 72: 220-224.

49. Houghton PE, Kincaid CB, Campbell KE, Woodbury MG, Keast DH (2000) Photographic assessment of the appearance of chronic pressure and leg ulcers. Ostomy Wound Manage 46: 20-26, 28-30.

50. Bowling FL, King L, Paterson JA, Hu J, Lipsky BA, et al. (2011) Remote assessment of diabetic foot ulcers using a novel wound imaging system. Wound Repair Regen 19: 2530.

51. Gardner SE, Frantz RA, Specht JK, Johnson-Mekot JL, Buresh KA, et al. (2001) How accurate are chronic wound assessments using interactive video technology? Journal of Gerontological Nursing 27: 15-20.

52. Debray M, Couturier P, Greuillet F, Hohn C, Banerjee S, et al. (2001) A preliminary study of the feasibility of wound telecare for the elderly. J Telemed Telecare 7: 353-358.

53. Hofmann-Wellenhof R, Salmhofer W, Binder B, Okcu A, Kerl H, et al. (2006) Feasibility and acceptance of telemedicine for wound care in patients with chronic leg ulcers. J Telemed Telecare 12: 15-17.

54. Ratliff CR, Forch W (2005) Telehealth for wound management in long-term care. Ostomy Wound Manage 51: 40-45.

55. Halstead LS, Dang T, Elrod M, Convit RJ, Rosen MJ, et al. (2003) Teleassessment compared with live assessment of pressure ulcers in a wound clinic: a pilot study. Adv Skin Wound Care 16: 91-96.

56. Saffle JR, Edelman L, Theurer L, Morris SE, Cochran A (2009) Telemedicine evaluation of acute burns is accurate and cost-effective. J Trauma 67: 358-365.

57. Clegg A, Brown T, Engels D, Griffin P, Simonds D (2011) Telemedicine in a rural community hospital for remote wound care consultations. J Wound Ostomy Continence Nurs 38: 301-304.

58. Rasmussen BS, Froekjaer J, Bjerregaard MR, Lauritsen J, Hangaard J, et al. (2015) A Randomized Controlled Trial Comparing Telemedical and Standard Outpatient Monitoring of Diabetic Foot Ulcers. Diabetes Care 38: 1723-1729.

59. Braun RP, Vecchietti JL, Thomas L, Prins C, French LE, et al. (2005) Telemedical wound care using a new generation of mobile telephones: a feasibility study. Arch Dermatol 141: 254-258. 
60. Rintala DH, Krouskop TA, Wright JV, Garber SL, Frnka J, et al. (2004) Telerehabilitation for veterans with a lower-limb amputation or ulcer: Technical acceptability of data. J Rehabil Res Dev 41: 481-490.

61. Rees RS, Bashshur N (2007) The effects of TeleWound management on use of service and financial outcomes. Telemed J E Health 13: 663-674.

62. Lewis P, McCann R, Hidalgo P, Gorma M (1997) Use of store and forward technology for vascular nursing teleconsultation service. Journal of Vascular Nursing 15: 116-123.

63. Wirthlin DJ, Buradagunta S, Edwards RA, Brewster DC Cambria RP, et al. (1998) Telemedicine in vascular surgery: feasibility of digital imaging for remote management of wounds. J Vasc Surg 27: 1089-1100.
64. Mass M Johnson-Mekota JL, Buresh KA, Gardner SE, Frantz RA, Specht JK, et al. (2001) A nursing application of telecommunications. Measurement of satisfaction for patients and providers. J Gerontol Nurs 27: 28-33.

65. Chan LN, Lai CK (2014) The effect of patient education with telephone follow-up on wound healing in adult patients with clean wounds: a randomized controlled trial. J Wound Ostomy Continence Nurs 41: 345-355.

66. Hill ML, Cronkite RC, Ota DT, Yao EC, Kiratli BJ (2009) Validation of hometelehealth for pressure ulcer assessment: a study in patients with spinal cord injury. J Telemed Telecare 15: 196-202.

67. Salmhofer W, Hofmann-Wellenhof R, Gabler G, Rieger-Engelbogen K, Gunegger D, et al. (2005) Wound teleconsultation in patients with chronic leg ulcers. Dermatology 210 : 211-217. 